\title{
Vertical Leg Drainage of Odema in Treatment of Leg Ulcers
}

\author{
I. H. J. BOURNE
}

British Medical fournal, 1974, 2, 581-583

Since oedema of adjacent tissue is a major factor in preventing healing of leg ulcers conservative treatment should aim to dry out the ulcer area before bandaging and to keep it dry afterwards. A method of postural drainage of oedema is described in which the patient lies supine with the legs raised vertically for two days. Nonstretch Viscopaste bandages are then applied and the patient allowed to move about normally, but instructed to continue vertical leg drainage for a period each day. Out of 106 cases treated by this method the leg ulcer healed within a year in $82(77 \cdot 4 \%)$. Relapses were apt to occur when the patient neglected to continue the vertical drainage regimen after the ulcer had healed. These results compare well with those reported for other methods of treatment. Vertical leg drainage treatment is inexpensive and the patient can continue at work.

\section{Introduction}

Much attention has been paid to the problem in cases of leg ulcer of freeing the limb from oedema, especially before applying bandages. Rivlin (1958) recommended that patients should sleep with the ends of their beds raised. Foote (1960) advised a period of bed rest to begin treatment, and he devised a special reclining chair for keeping the affected leg raised above heart level in a lifetime regimen of daily rest periods. Anning (1966) also advised rest in bed to abate oedema before bandaging, and Fegan (1971), with the same object, recommended resting with the leg raised for a day. Bor (1968) reported that all patients attending his ulcer clinic rested with their legs raised to 45 degrees for 20 minutes before bandages were applied, whereas Hunter (1971) admits patients to hospital for a week to rest in a bed with the end raised. Other ways of removing fluid from oedematous legs are massage (Bisgaard, 1948) and intermittent compression (Pflug, 1973). The need for ambulation after firm bandaging, to bring into play the pump function of the calf muscle, has been emphasized (Dodd and Cockett, 1956; Bassi, 1967; Fegan, 1971).

For many years I have treated leg ulcers on the principle that a swollen limb should be free of oedema before bandages are applied (Bourne, 1952). To this end I use a method of postural drainage known as the vertical leg drainage regimen. The preliminary period of drainage may be carried out at the weekend and thus does not interfere with the patient's normal working week. This paper describes the regimen and reviews the results in 112 patients treated during the period from January 1964 to August 1971.

\section{Patients}

Of the 112 patients 28 were seen in general practice and 84 at the Hammersmith Hospital leg ulcer clinic. As would be expected, nearly all were aged over 40 years and women (78)

Hornchurch, Essex, and Hammersmith Hospital, London W12 0HS

I. H. J. BOURNE, M.D., General Practitioner and Clinical Assistant in Charge of Leg Ulcer Clinic

outnumbered men (34) by more than two to one. In 48 cases (14 men and 34 women) the ulcer was associated with varicose veins, and in 30 cases ( 10 men and 20 women) with a previous deep vein thrombosis. Other aetiological factors were arterial disease in four cases (three men and one woman), accident in 14 cases (one man and 13 women), and various or unknown in 16 cases (six men and 10 women). Ulceration was bilateral in 18 cases and in nearly all cases there was eczema of the affected leg or legs. About half the patients were at work, and about half of the remainder were semi-retired.

\section{Method of Treatment}

Only those considered able to carry out the vertical leg drainage regimen were prescribed this treatment. Some patients who suffered from dyspnoea due to cardiac or respiratory disease were prescribed a modified regimen together with specific treatment for their illness.

The aims of treatment by vertical leg drainage before bandaging were explained to the patient, who was also given a pamphlet* describing in simple terms the regimen to be followed. This was that the legs had to be kept vertically raised during two whole days-a Saturday and Sunday being suggested as the least likely to interfere with the patient's normal occupation. Line drawings in the pamphlet illustrated the vertical leg position with the patient lying flat (fig. 1) and a modified position with the legs raised to 45 degrees and the head and shoulders resting on pillows (fig. 2). The patient was also asked to practise vertical leg drainage in the evening of each day of the week remaining before the weekend of continuous drainage. Time had to be spent in gaining the patient's understanding of the reason for postural drainage and its importance. The oedematous leg was likened to a wet blanket hanging on a line, in which the upper part dries more quickly as fluid seeps down with gravity. Middle aged and young people usually co-operated well, but a compromise had to be accepted with some of the elderly. So im-

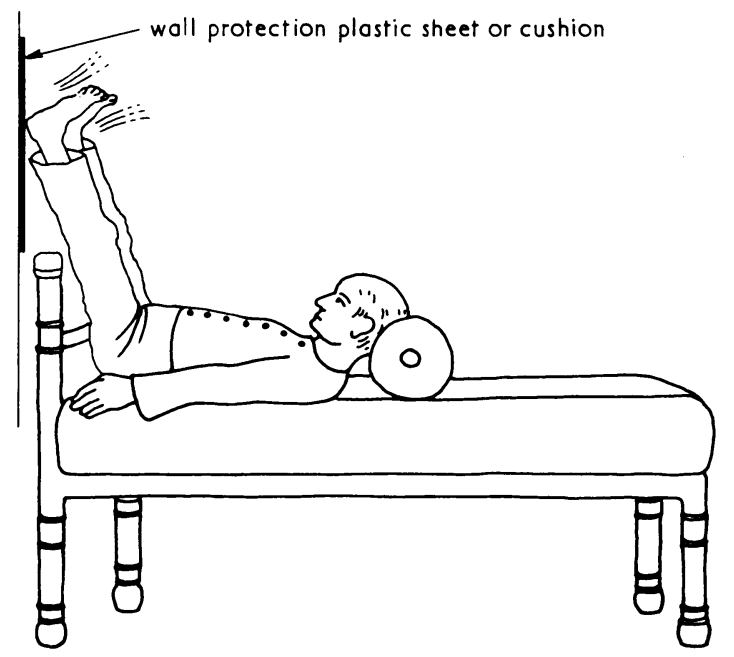

FIG. 1-Postural drainage with legs vertical.

*A copy of the pamphlet may be had on request to the author. 


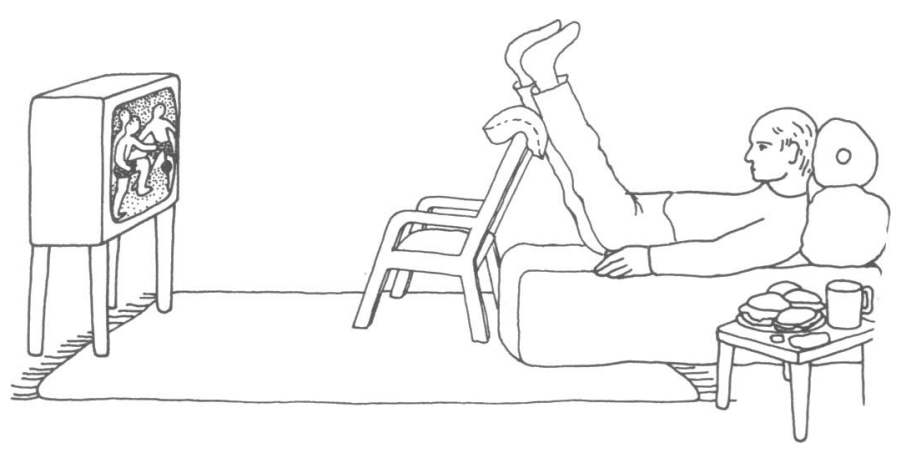

FIG. 2-Modified postural drainage with legs at $45^{\circ}$.

portant was it that a position as near to the vertical as possible was achieved that any effort by the patient was encouraged.

After the two days of postural drainage the affected leg, provided there was no evidence of residual oedema, was bandaged in the following way. The hip, knee, and ankle were flexed so that the calf muscles were relaxed and the instep creased (fig. 3). Two Viscopaste bandages were then applied, one over the other, from the toes to the knee. A plastic foam pad was placed over the ulcer and between the two Viscopaste bandages to increase pressure on the ulcer. After the Viscopaste one or two layers of crepe bandage were applied, starting tightly round the foot and ankle and easing the pressure as the knee was approached to avoid a garter effect. If after two days' vertical leg drainage some oedema remained bandaging was postponed until a further period of drainage had been effectual.

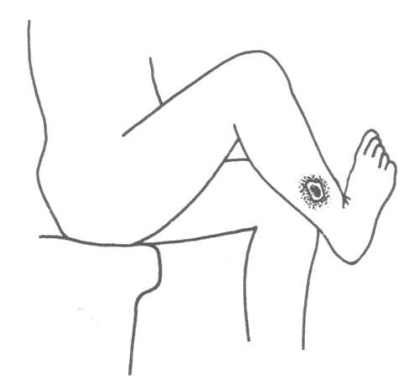

FIG. 3-Position of legs for bandaging.

In most cases the bandaging was done by a doctor or a district nurse. In the remainder-about $10 \%$ of cases-by a relative of the patient, following the instructions in the pamphlet. In $80 \%$ of the general practice cases I visited the patient at home on the Monday morning. Hospital clinic patients were mostly bandaged on the Sunday evening or the Monday morning by a district nurse or, in a few cases, by a relative. The general practitioner who referred the patient did the bandaging in about $20 \%$ of clinic cases, and in each case a copy of the pamphlet was sent to the doctor as well as given to the patient. All patients were instructed to carry out vertical leg drainage for at least one hour every day (usually in the evening for those at work) after the bandaging.

As a rule the bandages were removed after four weeks. The extent of healing of the ulcer was measured, and the bandages were replaced for another three months. In some cases the bandages had to be removed within a week, because of discomfort or offensive discharge. A much thinner leg was good evidence that the patient had been conscientiously practising daily postural drainage, and rebandaging with Viscopaste could be done at once. If the leg was still oedematous it was bandaged with only two crepe bandages, with a square of non-adhering plastic sheet to protect the ulcer, and the patient was advised to repeat the two-day vertical leg drainage regimen. Clinic patients who were unable to have the Viscopaste bandages applied properly at home were asked to return to the clinic for bandaging. With general practice cases it was easier to vary the treatment procedure to suit the circumstances and needs of the patient.

A few patients were unhappy with Viscopaste. They were bandaged with crepe bandages or wore elastic stockings. The importance of vertical leg drainage as the key to successful treatment was impressed on these patients even more than on those able to tolerate Viscopaste bandaging. Allergy to Viscopaste occurred in 10 patients. Viscopaste P.B.7 has been reported (Calnan, 1970; Perera, 1970) to be more allergenic than Viscopaste alone and was avoided.

Patients were told to report if the bandages were uncomfortable or if discoloration of the toes was seen. The latter was reported occasionally, but did not persist even in elderly patients with no dorsalis pedis pulsation. This led to greater confidence in prescribing treatment even in patients with thin legs and a presumptive diagnosis of "arterial leg ulcer." The need to move the ankle joint often was emphasized to all patients.

Antibiotics were prescribed in 13 cases of grossly infected ulcer, but in most they did not seem to aid healing. Diuretics given to nine patients with cardiac weakness or high blood pressure did not seem to play an important part in the treatment of their leg ulcer. Vitamin $\mathrm{C}$ was given to 10 patients, and in two in whom ascorbic acid excretion tests showed a deficiency a daily dose of $1,000 \mathrm{mg}$ vitamin $\mathrm{C}$ led to rapid healing of the ulcers.

\section{Results}

Six of the 112 patients in the series refused treatment. The analysis of results is therefore of 106 treated patients. Patients treated just before the end of the study period (August 1971) were followed up for a further six months until February 1972.

In the 106 patients treated the ulcer healed in $69(65.2 \%)$ and had not recurred by the end of the study period. In 13 patients $(12.3 \%)$ the ulcer healed, relapsed, and healed again by the end of one year, and was still healed at the end of the study period. Thus a total of 82 patients $(77 \cdot 4 \%)$ had been successfully treated. A further 17 patients $(16.0 \%)$ healed and relapsed and had not healed again by the end of the period. Thus the total number of cases of relapses was 30 out of $106(28.3 \%)$. Two patients failed to benefit and five had to discontinue treatment for various reasons.

\section{RATE OF HEALING}

In assessing rates of healing treatment was reckoned to have started on the date of the first examination, even when bandages were not applied until some days later. The date of healing was taken as the day when the ulcer was first seen to be healed on removing the bandages. Since most patients were seen at intervals of a month or more the date of healing could have been up to three weeks earlier than recorded, or more in some cases. All ulcers were measured in at least two directions with a special caliper. When there was more than one ulcer the largest was measured and used as the index of the rate of healing.

The size of the ulcers in the present series varied from $20 \mathrm{~mm}^{2}$ to $6,000 \mathrm{~mm}^{2}$, with a mean of $545 \mathrm{~mm}^{2}$. The mean healing rate-that is, reduction in area-of the average-size ulcer $\left(545 \mathrm{~mm}^{2}\right.$ ) was $6.8 \mathrm{~mm}^{2} /$ day whereas for an ulcer of $3,000 \mathrm{~mm}^{2}$ the rate was $36 \mathrm{~mm}^{2} /$ day. These rates are similar to those reported in other series (table). Patients in the 41-60 age group healed more slowly than older, retired patients. This might have been because retired patients were able to spend more time with their legs raised, or because many working people sit or stand all day in one place and the skin becomes oedematous owing to inactivity of the calf muscle pump. The 
healing rate was faster in the hospital clinic patients than in the general practice cases under my more immediate supervision.

At the end of treatment all patients, both healed and unhealed cases, who were thought to be in need of surgical treatment or sclerotherapy or needed further general investigation were referred to the surgeon in charge of the vascular clinic for assessment. The surgeon has always appreciated the value of having oedema-free legs to examine.

Rate of Healing of Leg Ulcers with Various Methods of Treatment

\begin{tabular}{|c|c|c|c|c|c|}
\hline \multirow[b]{2}{*}{ Series } & \multirow[b]{2}{*}{ Treatment } & \multirow[b]{2}{*}{$\begin{array}{l}\text { No. of } \\
\text { Cases }\end{array}$} & \multirow{2}{*}{$\begin{array}{c}\text { Mean } \\
\text { Size } \\
\text { of Ulcers } \\
\left(\mathrm{mm}^{2}\right)\end{array}$} & \multicolumn{2}{|c|}{ Mean Rate of Healing } \\
\hline & & & & $\overline{\mathrm{mm}^{2} / \text { Week }}$ & $\mathrm{mm}^{2} /$ Day \\
\hline Haeger (1964) & $\begin{array}{l}\text { Compression } \\
\text { and topical } \\
\text { medicaments }\end{array}$ & 91 & 545 & 56 & 8 \\
\hline $\begin{array}{l}\text { Fergusson and } \\
\text { Logan (1961) } \\
\text { Myers and }\end{array}$ & Bed rest & 271 & - & $27 \cdot 5$ & 3.9 \\
\hline Cherry (1971) & Comprcssion, & 51 & 3,001 & 489 & 70 \\
\hline Dourne $(19 / 4)$ & drainage & 106 & 545 & 55 & $6 \cdot 8$ \\
\hline
\end{tabular}

\section{Discussion}

Whatever the aetiology of a leg ulcer most present with oedema of the adjacent tissues. This is usually due to inefficient venous return caused by destruction of the valves in the perforating veins near the ulcer. After the patient has been up and about all day the ulcer edges are engorged with oedema fluid and toxic metabolites. The epithelial cells are swollen, fragile, and likely to die. When the patient goes to bed the oedema abates, conditions for epithelial growth become favourable, and the cells still living on the edges of the ulcer revive. The processes of damage and revival are repeated day after day. When the periods of destructive oedema are longer than the periods of abatement the ulcer enlarges. When the periods of dehydration are longer healing occurs. For this reason alone conservative treatment should concentrate on "drying out" the ulcer area and on keeping it dry. Bandages, therefore, should if possible never be applied to an oedematous leg. The rationale of vertical leg drainage is to dry out the leg before bandaging and then, together with bandaging with a non-stretch bandage, to keep the leg oedema-free during ambulation and healing.

Advantages of the vertical leg drainage treatment are, firstly, that it is carried out at home; secondly, after the first two days of continuous drainage the patient is ambulatory and can do whatever work he or she has to do; and thirdly, it is economical in time and money. The results with it compare favourably with the results of other methods of treatment (Fergusson and Logan, 1961; Haeger, 1964; Myers and Cherry, 1971).

Patience and persistance are needed by all for success in a treatment which depends so much on co-operation from the patient and the patient's relatives. Some patients find it difficult to grasp the fact that the vertical leg drainage regimen must be carried out indefinitely after the ulcer has healed. This accounted for some of the relapses in the present series. In most cases the patients were grateful for the advice given and were willing to carry it out. Even those who thought that "at my age" it was impossible to raise the legs at right angles to the recumbent body could be persuaded to do so when it was pointed out that sitting upright with the legs on another chair was exactly the same position, though in a different plane.

To face a lifetime of periodic resting with the legs vertical and the body horizontal is undoubtedly daunting, but most patients are prepared to do this rather than face the pain and odium of a leg ulcer. Recurrence is common in ulcers healed by any method of treatment. Nevertheless, a patient versed in the vertical leg drainage regimen always has a weapon with which to prevent a recurrence. Even those who have grown lax in continuing the regimen and suffered a recurrence as a result have cured themselves by at once returning to the path of duty.

The work reported here was the subject of a thesis for the M.D. of London University. I thank Professor James Calnan and Dr. Joseph Pflug, of Hammersmith Hospital, for their guidance and teaching and many other colleagues for their help. I also thank the North-east Metropolitan Regional Hospital Board for a grant.

\section{References}

Anning, S. T. (1966). British Medical fournal, 2, 1183.
Bassi, G. (1967). Les Varices de Membres Inferieurs, 2nd edn. Paris, Editions Bassi, G. (1967). Les Varices de Membres Inferieurs, 2nd edn. Paris, Editions
Doin.
Bisgaard, H. (1948). Ulcers and Eczema of the Leg after Phlebitis. Copenhagen, Bisgaard, H. (1948).

Bor, S. (1968). Nursing Times, 64, 906.

Bourne, I. J. H. (1952). Lancet, 1, 1260

Calnan, C. D. (1970). Transactions of the St. Fohn's Hospital Dermatological Society, $2,131$.

Dodd, H., and Cockett, F. B. (1956). The Pathology and Surgery of the Veins of the Lower Limb. London, Livingstone.

Fegan, W. G. (1971). Varicose Veins, Compression Sclerotherapy. London, Heinemann.

Fergusson, A. G., and Logan, J. C. P. (1961). British Medical fournal, 2, 870. Foote, R. (1960). Varicose Veins. Bristol, Wright.

Haeger, K. (1964). Acta Chirurgica Scandinavica, 128, 140.

Haeger, K. (1964). Acta Chirurgica Scandinavica, 128, 140.

Hunter, J. A. (1971). Recent Advances in Surgery, 1, 99. 3, 167.

Perera, P. (1970). Transactions of the St. Fohn's Hospital Dermatological Society, $2,174$.

Pflug, J. (1973). Personal communication.

Rivlin, S. (1958). Lancet, 1, 1363. 